University of Nebraska - Lincoln

DigitalCommons@University of Nebraska - Lincoln

Sociology Department, Faculty Publications

Sociology, Department of

$6-2010$

\title{
A comparison of homeless and high-risk young adults: Are they one and the same?
}

\author{
Kimberly A. Tyler \\ University of Nebraska-Lincoln, kim@ktresearch.net \\ Katherine A. Johnson \\ Kenexa, Lincoln, NE \\ Lisa A. Melander \\ University of Nebraska-Lincoln, Imeland@ksu.edu
}

Follow this and additional works at: https://digitalcommons.unl.edu/sociologyfacpub

Part of the Sociology Commons

Tyler, Kimberly A.; Johnson, Katherine A.; and Melander, Lisa A., "A comparison of homeless and high-risk young adults: Are they one and the same?" (2010). Sociology Department, Faculty Publications. 130.

https://digitalcommons.unl.edu/sociologyfacpub/130

This Article is brought to you for free and open access by the Sociology, Department of at DigitalCommons@University of Nebraska - Lincoln. It has been accepted for inclusion in Sociology Department, Faculty Publications by an authorized administrator of DigitalCommons@University of Nebraska - Lincoln. 


\title{
A comparison of homeless and high-risk young adults: Are they one and the same?
}

\author{
Kimberly A. Tyler, ${ }^{1}$ Katherine A. Johnson, ${ }^{2}$ and Lisa A. Melander ${ }^{1}$ \\ 1. Department of Sociology, University of Nebraska-Lincoln, Lincoln, NE, USA; \\ 2. Kenexa, Lincoln, NE, USA \\ Corresponding author - Kimberly A. Tyler, email kim@ktresearch.net
}

\begin{abstract}
Although experiencing poor parenting has been linked to high-risk behaviors and negative outcomes among different populations, very little research has been conducted on whether inadequate parenting has the same detrimental consequences for homeless and high-risk young adults. As such, this article compares homeless and marginally housed young adults to see if the associations between poor parenting (e.g. lower monitoring, neglect and physical abuse) and negative outcomes including depressive symptoms, victimization, delinquency, and substance use are similar for these two groups. The sample consisted of 199 homeless and high-risk young adults from the Midwestern United States. Multivariate results revealed that childhood sexual abuse was correlated with physical and sexual victimization and delinquency among marginally housed young adults. Among homeless individuals, neglect and physical abuse were associated with physical victimization and delinquency, respectively. Caretaker monitoring was linked with delinquency and substance use among both groups. Finally, caretaker substance misuse was related positively with higher levels of substance use, but only among marginally housed individuals. The results are discussed in terms of policy implications.
\end{abstract}

Keywords: homeless, high-risk young adults, poor parenting, negative outcomes

\section{Introduction}

It is estimated that as many as 2.8 million runaway and homeless youth live on the streets of America every day (National Runaway Switchboard, 2001). Homelessness is a dynamic situation that is difficult to define and is highly fluid, as it ranges on a continuum from transitional living situations to shelter life or living on the street (Tyler \& Whitbeck, 2004). Marginally housed youth, which may include those who have runaway histories or are in temporary housing arrangements, may be one step away from being out on the street. Therefore, it is important to examine homeless and marginally housed individuals, because both grow up with negative home environments which may lead to high-risk outcomes.

Children who grow up with less than optimal parenting have been found to engage in higher risk behaviors and also experience more negative outcomes compared to those with more positive parenting experiences. Research that has examined homeless or general populations tend to find 
that poor parenting (i.e. child maltreatment, lower levels of parental monitoring and parental substance misuse) is related to delinquency, substance use, depressive symptoms and/or victimization (Barnes \& Farrell, 1992; Cauce et al., 1998; Flannery, Williams, \& Vazsonyi, 1999; Kaplow, Curran, Dodge, \& the Conduct Problems Prevention Research Group, 2002; Kaufman \& Spatz Widom, 1999; McMorris, Tyler, Whitbeck, \& Hoyt, 2002; Tyler, 2002; Tyler \& Cauce, 2002; Windle, 1996). Even though this research has not compared homeless to other similarly situated high-risk youth, some comparison studies exist but their findings have generally been mixed. Some researchers have found differences between homeless youth and adults in terms of child abuse (Robert, Pauze, \& Fournier, 2005), substance use (McCaskill, Toro, \& Wolfe, 1998) and behavioral problems (Koblinsky, Gordon, \& Anderson, 2000). For example, Kushel, Evans, Perry, Robertson, and Moss (2003) found that homeless men and women experienced significantly more physical and/ or sexual victimization compared to marginally housed men and women. Others, however, have not found differences in terms of the effect of negative childhood experiences on outcomes between homeless and marginally housed individuals (Bassuk et al., 1996; Goodman, 1991; Schteingart, Molnar, Klein, Lowe, \& Hartmann, 1995; Wagner \& Perrine, 1994; Wolfe, Toro, \& McCaskill, 1999). Although McCaskill and colleagues (1998) found higher rates of alcohol abuse among homeless adolescents compared to their housed counterparts, there was no difference between groups in terms of depression and drug usage.

Although there is a limited body of research that compares homeless to other housed groups, it is currently unknown whether inadequate parenting has the same negative consequences for young people who are homeless compared to those who are marginally housed. As such, the purpose of this article is to compare homeless and marginally housed young adults to determine whether the associations between poor parenting (e.g. lower monitoring, neglect and physical abuse) and negative outcomes, including depressive symptoms, victimization, delinquency and substance use, are similar for these two groups. Learning more about these negative outcomes is important, because they may persist over time and affect overall functioning and well-being for both these groups. Furthermore, this study may have important implications for intervention, given that many young people who have experienced poor parenting are marginally housed and may not be receiving appropriate treatment.

\section{Method}

\section{Data}

Data are from the Homeless Young Adult Project (HYAP), a pilot study designed to examine the effect of neglect and abuse histories on homeless young adults' mental health and high-risk behaviors. From April 2004 to June 2005, 199 young adults were interviewed in three Midwestern cities. Of this total, 144 were homeless and 55 were marginally housed at the time of the interview. Those comprising the marginally housed sample were obtained via peer nominations from the homeless individuals. "Homeless" was defined as those currently residing in a shelter, on the street, or those living independently (e.g. with friends) because they had run away, had been pushed out, or had drifted out of their family of origin. Experienced interviewers who have served for several years in agencies and shelters that support homeless young people and are very familiar with local street cultures (e.g. knowledgeable about where to locate youth) conducted the interviews. Additionally, all interviewers had completed the Collaborative Institutional Review Board (IRB) Training Initiative course for the protection of human participants in research. 


\section{Procedure}

Interviewers approached shelter residents and located eligible homeless respondents in areas where street people congregate. Study eligibility for this portion of the sample required young people to be between the ages of 19 and 26 years and homeless. Interviewers obtained informed consent from young adults prior to participation, and told them about the confidentiality of the study and that their participation was voluntary. The interviews, which were conducted in shelter interview rooms or quiet corners of fast-food restaurants or coffee shops, lasted approximately one hour and all participants received $\$ 25$ for their involvement. Referrals for shelter, counseling services, and food services were offered at the time of the interview. Although interviewers did not tally screening rates formally, they reported that very few young adults refused to participate. The IRB at the University of Nebraska-Lincoln approved this study.

\section{Measures}

Physical abuse was measured with the Conflict Tactics Scale-Parent Child (CTSPC) (Straus, Hamby, Finkelhor, Moore, \& Runyan, 1998). Respondents were asked how many times their caretaker had engaged in a variety of abusive actions towards them before they were 18 years old (e.g. slapping them, kicking them and assaulting them with a knife or gun). Cronbach's alpha was 0.88. Due to skew, the 16 individual items were first dichotomized $(0=$ never and $1=$ at least once $)$ and then summed with a higher score, indicating more physical abuse.

Sexual abuse was measured using seven items (adapted from Whitbeck \& Simons, 1990). Young people were asked, for example: "Before you were on your own (when you were under 18), how often has any adult or someone at least five years older than you touched you sexually, like on your butt, thigh, breast or genitals ('private parts')?". Due to skew, the final variable was dichotomized into $0=$ no sexual abuse and $1=$ experienced sexual abuse at least once.

Neglect was comprised of five items from a supplementary scale within the CTSPC (Straus et al., 1998). These items asked respondents, for example, how often their caretaker was not able to give them the food they needed. Alpha reliability was 0.82 . Due to skew, the individual items were first dichotomized $(0=$ never and $1=$ at least once) and then summed, with a higher score indicating more neglect.

Caretaker monitoring was measured using nine items. Respondents were asked, for example, whether their caretaker knew the parents of their friends and if their caretaker knew where they were after school. Response categories included $0=$ never, $1=$ rarely, $2=$ sometimes, $3=$ most of the time and $4=$ always. These items were summed with a higher score indicating higher levels of monitoring. The scale ranged from 0 to 36 and the alpha reliability was 0.88 .

Caretaker substance misuse was measured using six items. Respondents were asked, for example, if they had ever thought their caretaker had a drinking problem and if they ever argued or fought with their caretaker when he/she was high. All responses were coded $0=$ no, $1=$ yes. A summed scale was created that ranged from 0 to 6 with an alpha reliability of 0.76 .

Depressive symptoms consisted of 10 items from a short form of the Center for Epidemiological Studies Depression Scale (Radloff, 1977). Respondents were asked, for example, how many days in the previous week they were bothered by things that do not usually bother them. Responses ranged from $0=$ rarely or none of the time (less than one day) to $3=$ most or all the time (five-seven days). Certain items were reverse-coded and then summed, so that higher scores indicated more depressive symptoms. The alpha reliability was 0.80 .

Physical victimization was measured with six items that asked respondents, for example, how many times they had something stolen from them, been beaten up, and been robbed. Alpha reliability was 0.77 . A summed scale was created with a range of 0-17. 
Sexual victimization was comprised of four items that focused upon the frequency with which respondents had unwanted sexual experiences. Items included, for example, having been touched sexually when they did not want to be and having been sexually assaulted and/or raped. Alpha reliability was 0.84 . Due to skew, each item was dichotomized and then summed to create an index where a higher score indicated more sexual victimization.

Delinquency was measured with 14 items. Respondents were asked how often they had engaged in a series of delinquent behaviors including theft, fraud, and violence (adapted from Whitbeck \& Simons, 1990). Alpha reliability was 0.88. Due to skew, the items were dichotomized and an index was created where higher scores indicated a greater number of different types of delinquency.

Substance use was measured by combining 12 individual variables that asked respondents how often they had drunk beer, wine, or liquor, had used marijuana or had used 'crank,' amphetamines, cocaine, opiates, hallucinogens, barbiturates, inhalants, or designer drugs in the past year. Alpha reliability was 0.79 . A mean scale was created with a potential range of $0=$ never to $4=$ daily.

Respondent type was coded $0=$ homeless and $1=$ marginally housed. Finally, gender was coded as $0=$ male and 1 = female [none of the variables included in the analyses were skewed and multicollinearity was not an issue, as all variance inflation factors were well below five (Menard, 1995)]. Frequencies, means, and standard deviations of all variables for both homeless and marginally housed individuals are presented in Table 1.

Results

\section{Multivariate analyses}

In order to be able to compare two groups simultaneously on the association between poor parenting and negative outcomes, a fully recursive multiple-groups path model was estimated using

Table 1. Differences between homeless and housed.

\begin{tabular}{|c|c|c|c|c|c|}
\hline & \multicolumn{2}{|c|}{ Homeless } & \multicolumn{2}{|c|}{ Housed } & \multirow[b]{2}{*}{$\chi^{2}$ comparison $^{\mathrm{a}}$} \\
\hline & $n$ & $\%$ & $n$ & $\%$ & \\
\hline \multicolumn{6}{|l|}{ Gender } \\
\hline Female & 46 & 31.9 & 39 & 70.9 & $24.694^{* * *}$ \\
\hline Male & 98 & 68.1 & 16 & 29.1 & \\
\hline \multicolumn{6}{|l|}{ Sexual abuse } \\
\hline No & 79 & 54.9 & 29 & 52.7 & 0.073 \\
\hline \multirow[t]{2}{*}{ Yes } & 65 & 45.1 & 26 & 47.3 & \\
\hline & Mean & SD & Mean & SD & Mean difference $^{b}$ \\
\hline Physical abuse & 6.00 & 3.48 & 5.22 & 3.64 & 1.397 \\
\hline Neglect & 2.10 & 1.71 & 2.00 & 1.68 & 0.387 \\
\hline Monitoring & 20.35 & 9.04 & 23.45 & 8.39 & $-2.210^{*}$ \\
\hline Caretaker substance misuse & 1.17 & 1.64 & 1.13 & 1.48 & 0.160 \\
\hline Depressive symptoms & 12.92 & 6.75 & 11.15 & 5.97 & 1.705 \\
\hline Physical victimization & 5.79 & 4.14 & 5.42 & 3.58 & 0.587 \\
\hline Sexual victimization & 0.70 & 1.18 & 1.38 & 1.65 & $-3.210^{* *}$ \\
\hline Delinquency & 3.49 & 3.55 & 3.38 & 3.19 & 0.190 \\
\hline Substance use & 0.57 & 0.48 & 0.40 & 0.42 & $2.222^{*}$ \\
\hline
\end{tabular}

a. $\chi^{2}$ comparison between homeless and housed

b. difference between homeless and housed ( $t$-test used).

${ }^{* * *} p<0.001 ;{ }^{* *} p<0.01 ;{ }^{*} p<0.05 ; \mathrm{SD}=$ standard deviation. 
the maximum likelihood procedure in Mplus 5.1 (Muthén \& Muthén 1998-2007). For interpretation purposes, the standardized path coefficients $(\beta)$ reported below represent the effect of a given predictor variable on the dependent variable after accounting for the remaining relationships in the model. Although ordinary least squares regression would also give us the standardized effect (i.e. $\beta$ ), multiple-groups models allow us to compare the two groups and estimate all the paths simultaneously.

Results for the path analysis (only significant paths given) are shown in Figure 1. The numbers in the figure are standardized beta coefficients. The paths for homeless and marginally housed respondents are represented by dashed lines and solid lines, respectively. Among homeless young adults, higher levels of depressive symptoms was associated with physical abuse $(\beta=0.32)$, while frequency of physical victimization was correlated positively with neglect $(\beta=0.27)$. Females were likely to have experienced greater sexual victimization $(\beta=0.34)$. Those who had experienced more frequent physical abuse were likely to have reported involvement in a greater number of different types of delinquent activities $(\beta=0.20)$ and to have lower levels of parental monitoring $(\beta=-0.22)$. Finally, males $(\beta=-0.16)$ and those who had experienced lower parental monitoring $(\beta=-0.25)$ were likely to have more frequent substance use. While some of these coefficients range from small to moderate (Cohen, 1988), they are statistically significant despite a limited sample size and multiple-group design. This lends additional credence to our findings .

Among marginally housed young adults (see Figure 1), those who reported higher levels of depressive symptoms were likely to be female $(\beta=0.39)$ and were likely to have experienced more frequent physical abuse $(\beta=0.29)$ and more neglect $(\beta=0.32)$. Additionally, those who reported having experienced greater physical victimization were more likely to have a history of sexual abuse $(\beta=0.28)$ and lower parental monitoring $(\beta=-0.22)$, whereas more sexual victimization was associated with being female $(\beta=0.27)$ and having experienced sexual abuse $(\beta=0.46)$. Young adults who engaged in a greater number of delinquent acts were likely to have a history of sexual abuse $(\beta=0.23)$ and lower parental monitoring $(\beta=-0.37)$. Finally, more substance use among young adults was linked to lower levels of monitoring $(\beta=-0.31)$ and higher levels of caretaker substance misuse $(\beta=0.25)$.

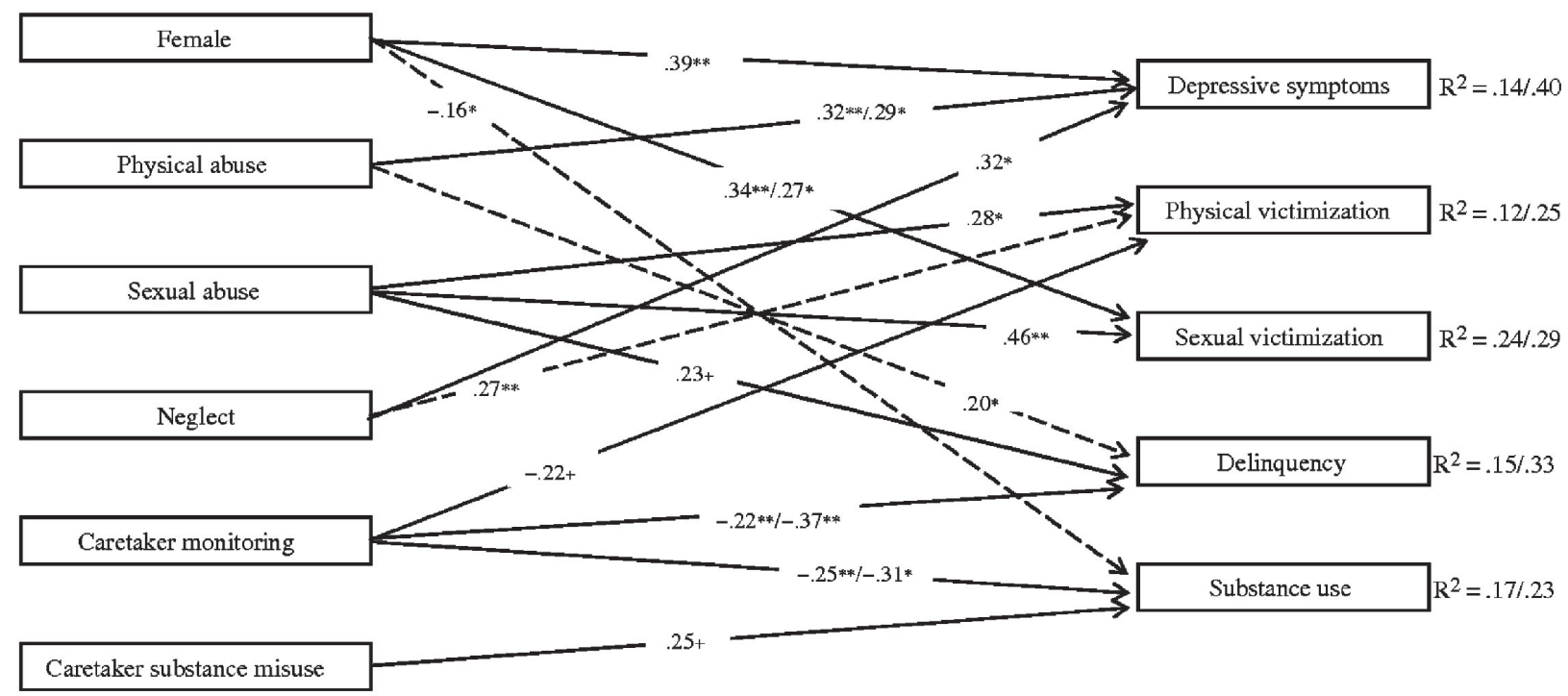

Figure 1. Standardized path coefficients for homeless $(n=144)$ and marginally housed $(n=55)$. ${ }^{* *} P<.01 ;{ }^{*} P<.05 ;+$ $P<.10$. The paths for homeless respondents are represented by dashed lines; the paths for marginally housed are signified by solid lines. When two coefficients are provided, the coefficient for homeless is listed first. 


\section{Discussion}

The purpose of this article was to compare homeless and marginally housed young adults to determine whether the associations between poor parenting and negative outcomes, including depressive symptoms, victimization, delinquency, and substance use, are similar for these two groups. Overall, the results indicate that inadequate parenting is linked to numerous negative outcomes among both homeless and marginally housed young people, although the paths that are significant vary somewhat between groups. For homeless individuals, females are more likely to experience higher levels of sexual victimization, whereas males are more likely to have higher levels of substance use. Physical abuse is a correlate of delinquency and depressive symptoms, whereas neglect is linked to physical victimization. Finally, lower levels of monitoring are related to more substance use and delinquency among homeless individuals. All these results are in the expected direction and are generally consistent with the larger literature on homeless young people (Cauce $e t$ al., 1998; Kaufman, \& Spatz Widom, 1999; McMorris et al., 2002; Tyler \& Cauce, 2002; Tyler, Hoyt, Whitbeck, \& Cauce, 2001).

For the marginally housed individuals, a somewhat different set of relationships are significant. Higher levels of depressive symptoms are associated with being female and having experienced more physical abuse and neglect. Additionally, those with a history of sexual abuse are more likely to have been sexually and physically victimized and to have engaged in more delinquent acts, indicating that the impact of early child maltreatment can have lasting effects. Marginally housed females also experienced more sexual victimization compared to their male counterparts. Caretaker monitoring was especially important for this group: those with lower levels of monitoring were more likely to be delinquent, to have experienced more physical victimization and to have used more substances. Finally, marginally housed respondents who reported higher substance misuse among their caretakers were more likely to have higher rates of alcohol and drug usage. These results are also in the expected direction and consistent with the literature on the general population (Barnes \& Farrell, 1992; Flannery et al., 1999; Kaplow et al., 2002; Windle, 1996).

Some limitations should be noted. First, all data are based on self-reports. Despite this, participants were informed that their responses would be confidential and the interviewers were already known and trusted by many of the young people, so it is less likely that the respondents would be motivated to bias their responses. Another limitation is the retrospective nature of many of the measures, which may have resulted in some over- or underreporting. Thirdly, this study was cross-sectional; therefore, inferences about causality cannot be made. Finally, some of the marginally housed sample had a history of running away. Although this introduces the possibility of overlap between the groups, the designation was based upon the young adult's housing status at the time of the interview and thus can be seen as a true, qualitative difference.

Our results offer some unique insight into the relationships between poor parenting and negative outcomes among homeless and marginally housed young adults. Specifically, the results indicate that many of the relationships between family risk factors and negative outcomes are similar for both groups. Regardless of housing status females, for example, are at higher risk for sexual victimization, whereas lower caretaker monitoring is associated with higher delinquency participation and more substance use. Experiencing more physical abuse is also correlated with more depressive symptoms among both homeless and marginally housed individuals. Overall, the results suggest that the distinctions between homeless and marginally housed young adults are fluid, with considerable overlap. In other words, although these two groups may not be one and the same, they both come from inadequate family environments where the effects of poor parenting continue to impact these young people in a negative manner. Further, results from this study indicate that being marginally housed 
does not exempt young people from the deleterious outcomes of poor mental health, victimization, and high-risk behaviors.

At the policy level, the current findings have practical implications for service providers and researchers. The high rates of child maltreatment and lower levels of caretaker monitoring experienced by both homeless and marginally housed young adults in this study suggest that service providers need to be sensitive to the concerns and experiences of all victims, regardless of housing status, in order to help them adequately recover. Programs are also needed to build young people's sense of self-worth, teach them about healthy relationships and develop healthy coping styles. Without such programs, many young adults with histories of maltreatment are at risk for entering violent relationships where they will sustain further abuse. Additionally, some may continue to turn to substance use as a way of coping, perhaps modeling the behaviors of their caretakers who misuse substances. Healthy and realistic coping styles are needed to break the chain of violence, regardless of housing status, so that young people are not destined for long-term victimization or homelessness. Furthermore, intervention programs are needed to help guide young people through this critical transition period during which work patterns are established and intimate relationships are formed. Doing so may ultimately help at-risk youth to establish themselves as healthy young adults .

Acknowledgments - This research was supported by the National Institute of Mental Health grant number K01MH064897, Dr. Kimberly A. Tyler, Principal Investigator.

\section{References}

Barnes, G. M., \& Farrell, M. P. (1992). Parental support and control as predictors of adolescent drinking, delinquency, and related problem behaviors. Journal of Marriage and the Family, 54, 763-776.

Bassuk, E. L., Weinreb, L. F., Buckner, J. C., Browne, A., Salomon, A., \& Bassuk, S. S. (1996). The characteristics and needs of sheltered homeless and low-income housed mothers. Journal of the American Medical Association, 276, 640-646.

Cauce, A.M., Paradise, M., Embry, L., Morgan, C. J., Lohr, Y., Theofelis, J., Heger, J., \& Wagner, V. (1998). Homeless youth in Seattle: Youth characteristics, mental health needs, and intensive case management. In K. Kutash, A. Duchnowski, \& M. Epstein, eds., Community-Based Programming for Children with Serious Emotional Disturbances: Research and Evaluation (pp. 611-632). Baltimore, MD: Brookes Publishing.

Cohen, J. (1988). Statistical Power Analysis for the Behavioral Sciences. Hillsdale, NJ: Erlbaum.

Flannery, D. J., Williams, L. L., \& Vazsonyi, A. T. (1999). Who are they with and what are they doing? Delinquent behavior, substance abuse, and early adolescents' after-school time. American Journal of Orthopsychiatry, 69, 247-253.

Goodman, L.A. (1991). The prevalence of abuse among homeless and housed poor mothers: A comparison study. American Journal of Orthopsychiatry, 61, 489-500.

Kaplow, J. B., Curran, P. J., Dodge, K. A., \& the Conduct Problems Prevention Research Group. (2002). Child, parent, and peer predictors of early-onset substance use: A multisite longitudinal study. Journal of Abnormal Psychology, 30, 199-216.

Kaufman, J. G., \& Spatz Widom, C. (1999). Childhood victimization, running away, and delinquency. Journal of Research in Crime and Delinquency, 36, 347-370.

Koblinsky, S. A., Gordon, A. L., \& Anderson, E. A. (2000). Changes in the social skills and behavior problems of homeless and housed children during the preschool year. Early Education and Development, 11, 321-337. 
Kushel, M. B., Evans, J. L., Perry, S., Robertson, M. J., \& Moss, A. R. (2003). No door to lock - Victimization among homeless and marginally housed persons. Archives of Internal Medicine, 163, 2492-2499.

McCaskill, P., Toro, P., \& Wolfe, S. (1998). Homeless and matched housed adolescents: A comparative study of psychopathology. Journal of Clinical Child Psychology, 27, 306-319.

McMorris, B. J., Tyler, K. A., Whitbeck, L. B., \& Hoyt, D. R. (2002). Familial and "on-the-street" risk factors associated with alcohol use among homeless and runaway adolescents. Journal of Studies on Alcohol, 63, 34-43.

Menard, S. (1995). Applied Logistic Regression Analysis. Thousand Oaks, CA: Sage.

Muthén, L. K., \& Muthén, B. O. (1998-2007). Mplus User's Guide, 4th edition. Los Angeles, CA: Muthén and Muthén.

National Runaway Switchboard. (2001). Welcome to the national runaway switchboard. Accessed September 30, 2009, from: http://www.nrscrisisline.org/

Radloff, L. S. (1977). The CES-D Scale: A self-report depression scale for research in the general population. Applied Psychological Measurement, 1, 385-401.

Robert, M., Pauze, R., \& Fournier, L. (2005). Factors associated with homelessness of adolescents under supervision of the youth protection system. Journal of Adolescence, 28, 215-230.

Schteingart, J. S., Molnar, J., Klein, T. P., Lowe, C. B., \& Hartmann, A. H. (1995). Homelessness and child functioning in the context of risk and protective factors moderating child outcomes. Journal of Clinical Child Psychology, 24, 320-331.

Straus, M. A., Hamby, S. L., Finkelhor, D., Moore, D. W., \& Runyan, D. (1998). Identification of child maltreatment with the Parent-Child Conflict Tactics Scales: Development and psychometric data for a national sample of American parents. Child Abuse and Neglect, 22, 249-270.

Tyler, K. A. (2002). Social and emotional outcomes of childhood sexual abuse: A review of recent research. Aggression and Violent Behavior, 7, 567-589.

Tyler, K. A., \& Cauce, A. M. (2002). Perpetrators of early physical and sexual abuse among homeless and runaway adolescents. Child Abuse and Neglect, 26, 1261-1274.

Tyler, K. A., Hoyt, D. R., Whitbeck, L. B., \& Cauce, A. M. (2001). The impact of childhood sexual abuse on later sexual victimization among runaway youth. Journal of Research on Adolescence, 11, 151-176.

Tyler, K. A., \& Whitbeck, L. B. (2004). Lost childhoods: Risk and resiliency among runaway and homeless adolescents. In P. Allen-Meares \& M. W. Fraser, eds., Intervention with Children and Adolescents: An Interdisciplinary Perspective (pp. 378-397). Boston: Pearson Education.

Wagner, J. K., \& Perrine, R. M. (1994). Women at risk for homelessness: Comparison between housed and homeless women. Psychological Reports, 75, 1671-1678.

Whitbeck, L. B., \& Simons, R. L. (1990). Life on the streets: The victimization of runaway and homeless adolescents. Youth and Society, 22, 108-125.

Windle, M. (1996). Effect of parental drinking on adolescents. Alcohol Health and Research World, 20, 181-184.

Wolfe, S. M., Toro, P. A., \& McCaskill, P. A. (1999). A comparison of homeless and matched housed adolescents on family environment variables. Journal of Research on Adolescence, 9, 53-66. 